\title{
ANALISIS PERUBAHAN TUTUPAN LAHAN HUTAN DI IUPHHK-HA PT. GEMA HUTAN LESTARI KABUPATEN BURU PROVINSI MALUKU
}

\section{ANALYSIS OF CHANGES FOREST LAND IN IUPHHK-HA PT. GEMA HUTAN LESTARI BURU DISTRICT MALUKU PROVINCE}

\author{
Ibnu R. Pattilouw ${ }^{1)}$, G. Mardiatmoko ${ }^{2)}$, Ferad. Puturuhu ${ }^{3)}$ \\ ${ }^{1)}$ Mahasiswa Program Pascasarjana Prodi Manajemen Hutan, Universitas Pattimura \\ ${ }^{1,2)}$ Dosen Program Pascasarjana Prodi Manajemen Hutan, Universitas Pattimura \\ E-mail: ibnupattilou@yahoo.com \\ \begin{tabular}{l|l} 
Diterima: 12 Mei 2019 & Disetujui: 30 Juli 2019
\end{tabular}
}

\begin{abstract}
Abstrak
Tujuan penelitian ini adalah: mengidentifikasi tutupan lahan, menganalisis perubahan tutupan lahan, menghitung laju degradasi hutan dan deforestasi, dan menentukan kebijakan pengelolaan hutan.. Penelitian ini dilakukan dengan menggunakan metode penginderaan jauh dan SIG untuk perolehan data perubahan tutupan lahan beberapa tahun dan melakukan pemetaan. Dari penelitian yang dilaksanakan diperoleh hasil klasifikasi tutupan lahan hutan menggunakan citra Landsat 8 OLI/TIRS tahun 2013, 2016, dan 2018 terdiri atas hutan, semak belukar, alang-alang, rawa, sungai dan lahan terbuka. Perubahan tutupan lahan tertinggi yang terjadi pada tahun 2013 sampai dengan tahun 2016 meliputi hutan berubah menjadi lahan terbuka sebesar 12261,75 ha. Semak belukar menjadi lahan terbuka juga mengalami perubahan yang besar seluas 12912,25 ha. Hutan yang mengalami degradasi sejak tahun 2013- 2016 seluas 17703,07 ha,
\end{abstract}

Kata Kunci: Analisis, Tutupan lahan, Multitemporal, Kawasan hutan

\begin{abstract}
The objectives of this study are: identifying land cover, analyzing land cover change, calculating the rate of forest degradation and deforestation, and determining forest management policies. This research was conducted using remote sensing methods and GIS for obtaining land cover change data for several years and conducting mapping. From the research conducted, the results of the classification of forest land cover using Landsat 8 OLI / TIRS imagery in 2013, 2016 and 2018 consisted of forests, shrubs, reeds, swamps, rivers and open land. The highest land cover change that occurred in 2013 up to 2016 covered forests turned into open land amounting to $12261.75 \mathrm{ha}$. Shrubs into open land also experienced a large change of 12912.25 ha. Forests that have been degraded since 2013-2016 covering an area of 17703.07 ha,
\end{abstract}

Keywords: Analysis, Land cover, Multitemporal, Forest area

\section{PENDAHULUAN}

$\begin{aligned} & \text { Indonesia merupakan negara } \\ & \text { ketiga luas hutan terbesar didunia }\end{aligned}$ setelah Brazil dan Kongo (WWF 2012). Luasan hutan yang terbesar di Indonesia ini Menurut Forest Watch Indonesia (FWI) berada di Kalimantan dan Sumatera sebagai provinsi yang mempunyai hutan potensial, karena paling banyak memiliki spesies pohon yang bernilai tinggi serta letaknya yang paling strategis. Penutup lahan (land cover) merupakan semua kenampakan fisik dan biologis yang menutupi lahan seperti vegetasi atau unsur-unsur buatan manusia (CFS, 2003), sedangkan menurut Comber et al (2005) 
penutup lahan adalah material fisik di permukaan bumi, termasuk di dalamnya rumput, aspal, pepohonan, tanah terbuka, air, dan lain-lain. Ada dua metode utama untuk memperoleh informasi tentang penutup lahan yaitu analisis atau interpretasi citra penginderaan jauh, dan survei lapangan. Penutup Hutan (Forest Coverage) adalah penutup lahan oleh vegetasi dengan komposisi dan kerapatan tertentu, sehingga dapat tercipta fungsi hutan antara lain iklim mikro, tata air, dan tempat hidup satwa sebagai satu ekosistem hutan. (UU Nomor 41 Tahun 1999).

Selama dua puluh tahun terakhir ini IUPHHK-HA PT Gema Hutani Lestari (PT. GHL), berupaya tetap menjaga keberadaan hutan dengan telah melaksanakan kegiatan pengelolaan hutan yang meliputi perencanaan, penananaman \& Rehabilitasi penanaman, penelitian dan pengembangan serta kewajiban kepada llingkungan dan masyarakat sesuai dengan tata waktunya dan terbukti pelaksanaan sesuai dengan teknis kegiatannya. Akan tetapi, sejalan dengan pertambahan penduduk didalam dan sekitar PT. GHL telah menyebabkan meningkatnya tekanan terhadap keberadaan hutan pada areal konsesi.

\section{METODE PENELITIAN}

Penelitian ini dilakukan di kawasan hutan IUPHHK-HA PT. Gema Hutan Lestari (PT. GHL) Kabupaten Buru Provinsi Maluku pada bulan Agustus -
Seiring perubahan zaman dan berkembangnya teknologi informasi yang pesat, banyak cara untuk mempermudah memperoleh informasi lokasi yaitu melalui penginderaan jauh dengan pemanfaatan data citra satelit dan menggunakan SIG (Sistem Informasi Geografis) (Puturuhu, 2017). Dengan menggunakan SIG kita dapat melihat peta yang berbasis sistem informasi, yang dapat menjelaskan lebih terperinci dan mempermudah pemahaman dari peta tersebut.

Kementerian kehutanan sudah sejak lama menggunakan citra landsat sebagai alat bantu dalam memantau kondisi hutan Indonesia (Wicaksono,2006). Citra landsat multi waktu/multitemporal yang dimanfaatkan dan dikombinasikan dengan SIG sangat baik untuk melakukan proses monitoring perubahan hutan, terutama hutan hujan sub tropika seperti di Indonesia dan Maluku yang umumnya kerapatannya tinggi. Berdasarkan uraian di atas, maka tujuan Penelitian ini adalah mengidentifikasi dan menganalisis perubahan tutupan lahan di areal hutan pada tahun 2006, 2012 dan 2018 di IUPHHK-HA PT. Gema Hutan Lestari Kabupaten Buru Provinsi Maluku.

Oktober 2018. Alat yang digunakan dalam penelitian ini adalah GPS, kompas, seperangkat komputer dan printer, serta alat tulis menulis, dan bahannya yaitu Citra Landsat 8 , peta batas administratif, peta 
RBI, serta peta batas kawasan hutan IUPHHK-HA PT. Gema Hutan Lestari.

Penelitian ini dilakukan dengan menggunakan metode analitik dimana citra satelit di dari tiga tahun berbeda tahun rekaman 2013, 2016 dan 2018 diinterpretasi secara digital melalui klasifikasi supervised. Setelah itu dilakukan pemetaan dengan menggunakan SIG untuk menganalisis perubahan tutupan lahan hutanya. Proses ini diawali dengan Pra Processing citra digital yaitu dengan cara mengisi citra yang dijadikan master dengan citra pengisi yang bisa saja keduanya memiliki stripping (banding) namun pada lokasi yang berbeda, sehingga dapat saling mengisi; melakukan koreksi geometrik (Rektifikasi) maupun radiometrik citra (Radiometric enhanchment).

Pengolahan citra digital untuk citra landsat 8 dilakukan melalui penyiapan citra mozaik, pembuatan citra komposit dan melakukan klasifikasi visual (on-screen digitation) dan klasifikasi digital untuk memperoleh kelas penutup lahan setiap tahun (2013, 2016 dan 2018). Dalam penelitian ini metode yang digunakan dalam analisis digital adalah metode peluang maksimum (Maximum likelihood

\section{HASIL DAN PEMBAHASAN}

\section{Keadaan Umum Lokasi Penelitian}

Lokasi penelitian terletak dalam wilayah kerja IUPHHK-HA PT. Gema Hutan Lestari. Secara geografis IUPHHK-HA PT. Gema Hutan Lestari classifier). Pada metode ini terdapat pertimbangan berbagai faktor, diantaranya adalah peluang dari suatu piksel untuk dikelaskan kedalam kelas atau kategori tertentu. (Lilesand TM, Kiefer RW. 1990).

Dalam klasifikasi diperlukan suatu penciri kelas. Penciri kelas ini adalah satu set data yang diperoleh dari suatu training area, ruang feature (feature space) atau klaster. Jumlah piksel yang harus diambil untuk training area pada masing-masing kelas adalah sebanyak jumlah band yang digunakan plus satu $(N+1)$ (Jaya 2010). Hasil analisis digital pada citra tahun 2013, 1016, dan 2018 yang merupakan data dalam bentuk raster yang kemudian diubah dalam bentuk vektor dan dilakukan overlay untuk menilai perubahan penutup lahan melalui analisis spasial pada SIG.

Pengecekan lapangan dilakukan dengan metode purposive sampling. Setiap titik didatangi kemudian dilakukan pendataan, pengamatan serta pencatatan informasi penting. Data yang diambil adalah data rekamam koordinat titik pengamatan lapangan dari GPS, kondisi tutupan lahan sekitar titik lapangan yang dilengkapi gambar dan hasil wawancara dengan masyarakat.

terletak diantara $30^{\circ} 20^{\prime}-3^{\circ} 38^{\prime}$ lintang selatan dan $126^{\circ} 06^{\prime}-129^{\circ} 29^{\prime}$ bujur timur dan buru selatan barat terletak antara $3^{\circ} 05^{\prime}$ $-3^{\circ} 27^{\prime}$ lintang selatan dan $126^{\circ} 16^{\prime}-126^{\circ}$ 51 ' Bujur Timur, dengan luas 148. $450 \mathrm{Ha}$. Ditinjau dari pembangian Daerah Aliran 
Sungai (DAS) areal kerja IUPHHK-HA PT. Selatan Barat terletak dalam DAS Sungai Gema Hutan Lestari meliputi Hutan Buru Waemasi, Sungai Waemala dan Sungai Utara terletak dalam DAS sungai Wainibe Waenalut. dan sungai Waepoti dan Hutan Buru

Tabel 1. Kondisi Penutupan Lahan Menurut Fungsi Hutan berdasarkan padu serasi TGHK/RTRWP Maluku dan penafsiran citra landsat areal IUPHHK-HA PT. Gema Hutan Lestari.

\begin{tabular}{|c|c|c|c|c|c|c|}
\hline \multirow[b]{2}{*}{ Penutupan Lahan } & \multicolumn{4}{|c|}{ Fungsi Hutan } & \multirow{2}{*}{$\begin{array}{l}\text { Bufer } \\
\text { Zone } \\
\text { (Ha) }\end{array}$} & \multirow[b]{2}{*}{ Jumlah } \\
\hline & $\begin{array}{l}\mathrm{HL} \\
\text { (Ha) }\end{array}$ & $\begin{array}{l}\text { HPT } \\
(\mathrm{Ha})\end{array}$ & $\begin{array}{l}\text { HP } \\
\text { (ha) }\end{array}$ & $\begin{array}{l}\text { HPK } \\
\text { (Ha) }\end{array}$ & & \\
\hline Hutan Primer & 148 & 12.022 & 1.474 & 3.592 & 4.087 & 21.323 \\
\hline Hutan Bekas & 17 & 44.280 & 18.530 & 13.914 & 5.831 & 82.572 \\
\hline Tebangan & & & & & & \\
\hline Non Hutan & - & 15.195 & 17.018 & 5.434 & 1.668 & 39.315 \\
\hline Tertutup Awan & 1.220 & 1.174 & 1.124 & 892 & 830 & 5.240 \\
\hline Jumlah & 1.385 & 72.671 & 38.146 & 23.896 & 12.416 & 148.450 \\
\hline
\end{tabular}

Areal IUPHHK-HA PT.Gema

Hutan Lestari memiliki kondisi topografi datar sampai dengan sangat curam. Dari hasil pengukuran kelerangan memiliki topografi dengan prosentase kelengan 0 $-8 \%$ sampai dengan sangat curam dengan kelerangan diatas $40 \%$.

Berdasarkan Peta Geologi Indonesia Skala 1 : 250.000 (Direktorat Geologi Bandung 1968) menunjukan bahwa formasi geologi yang menyusun areal IUPHHK-HA PT. Gema Hutan Lestari terdiri dari batuan Sedimen: Aluvium, dan terumbu koral yang terdapat didaerah pesisir utara dan barat, muara sungai Waeputih dan sekitar leksula. a) Sekis hablur yang terdapat diantara DAS Waeputih - Waenibe Danau Rana dan sekitar kampong kayeli. b) Tia yang terdapat didaerah sebelah utara Namrole, Waeula, diantara Danau Rana Noezoikum tak dibedakan terdapat didaerah sebelah
Utara Waepandan dan di tengah pulau Buru. c) Baman Sedimen Neogen diantara aliran sungai Waekuma dan gunung Domot dan beberapa lokasi kecil lainnya. Danau kunturan dan sedekit disekitar Gunung Kapala Madang, dan d) Noezoikum terdapat didaerah sebelah Utara Waepandan (leko) dan ditengah aliran sungai waekuma dan gunung Domot dan beberapa lokasi kecil lainnya.

Menurut peta tanah Maluku 1 : 100.000 (Pusat Penelitian Tanah, Bogor, 1993), jenis tanah di areal IUPHHK-HA PT. Gema Hutan Lestari didominasi tanah Podsolik, Fisiografi angkatan (Uplit mountain), meliputi alluvial, terdapat diantara perbukitan dalam luasan terbatas. Sedangkan tekstur tanah lokasi penebangan terdiri dari liat (clay) dan liat berpasir (sandy clay). Pada tanah dibawah tegakan hutan sebagian tanahnya bertekstur lempung berliat (clay loamy).Iklim di pulau 
ini dipengaruhi oleh sisitim sirkulasi angin monson dari samudera Pasifik dan philipina. Menurut sistem klasifikasi iklim Schmidt dan Ferguson (1951), berdasarkan data iklim yang diperoleh dari stasiun Berdasarkan data curah hujan tahunan yang diperoleh dari stasiun tersebut, dimana curah hujan di daerah pantai tergolong rendah - sedang dengan instesitas \pm 1.429 atm/tahun, rata-rata jumlah hari hujan sebesar 7 hari/bulan, bulan kering terjadi pada bulan September dengan rata-rata hari hujan 6 hari/bulan. Suhu bulanan berkisar antara $25,9^{\circ} \mathrm{C}-$ $27,8^{\circ} \mathrm{C}$ dengan suhu rata-rata bulanan tertinggi pada bulan Desember.

Kelompok Hutan Pulau Buru bagian barat berdasarkan tipe iklimnya maka wilayah bagian utara termasuk dalam tipe hutan musim (monsoon forest/tropical moist deciduous forest), sedangkan bagian selatan termasuk tipe hutan hujan tropika bawah (low land evergreen tropical rain forest). Secara umum penyebaran potensi pada kedua kelompok hutan tersebut didominasi oleh jenis meranti (shorea Sp) dari family Dipterocarpaceae dengan potensi tegakan $64,82 \mathrm{M}^{3} / \mathrm{Ha}(89,2 \%)$ yang meliputi meranti merah terapung (Shorea selanica) dan meranti merah tenggelam (Shorea platicarpa Mei). Jenis-jenis lain yang banyak terdapat diantaranya kayu putih (Melaleuca leucadendron) dengan potensi $2.53 \mathrm{M}^{3} / \mathrm{Ha}(2,3 \%)$ dan Uhun (Eucaliptosis papuana CT) $2,46 \mathrm{M}^{3} / \mathrm{Ha}(4,00 \%)$.
Klimatologi Wae Apo, areal IUPHHK-HA PT. Gema Hutan Lestari termasuk tipe iklim $\mathrm{C}$ dengan nilai $\mathrm{Q}=1 \%$. Daerah pedalaman mungkin lebih basah karena curah hujan lebih tinggi.

Berdasarkan Penelitian IPB Bogor areal IUPHHK-HA PT. Gema Hutan Lestari lokasi Waemutu, komposisi jenis dan tegakan hutan pada areal Petak Ukur Permanen (PUP) dan areal hutan primer di lokasi Waedanga, umumnya didominasi oleh kelompok jenis meranti (Shorea sp), Uhun (Eucaliptosis papuana CT), Sapin (Castanopsis buruana Miq), Hebet (Trema orientalis), Kenari (Canarium $\mathrm{sp}$ ), Jambu-jambuan (Eugenia sp), tingil (Garcinia sp), Bintangur (Colophyllum $\mathrm{sp}$ ), nani (Metrosideros petiolata Kds), Matoa (Pometia pinnata), pala hutan (Myristica fragans), Belo hitam (Diospyros piloshanera), Gupasa (Vitex cofassus), Nyatoh (palaqium spp), Katapang (Termanalis catappa L). Selain itu dapat juga ditemukan berbagai tumbuhan bawah, seperti bamboo, rotan, anggrek, tumbuhan obat, tumbuhan hias, serta berbagai jenis herba dan liana.

\section{Klasifikasi Tutupan Lahan pada Citra Landsat 8 OLI/TIRS Multitemporal}

Citra landsat 8 tahun 2013, 2016, dan 2018 yang di dapatkan memiliki kwalitas dan tutupan awan yang sedikit sehingga dapat diolah langsung secara digital dengan menggunakan metode Maximum likelihood calssification. Dengan cara ini penafsiran citra dapat dilakukan dalam jumlah banyak dan 
dalam waktu yang relatif singkat. kunci interpretasi citra landsat 8 Sebelum data diolah secara digital pada OLI/TIRS tahun 2013, 2016, dan 2018 software ArcGis version 10.3 terlebih diperoleh enam kelas penutup lahan dahulu dibuat training area sesuai kelas yang dikenali di lapangan. Hasil klasifikasi tutupan lahan berdasarkan yaitu hutan, semak belukar, alang-alang, tanah terbuka, sungai dan rawa (Gambar $1)$.

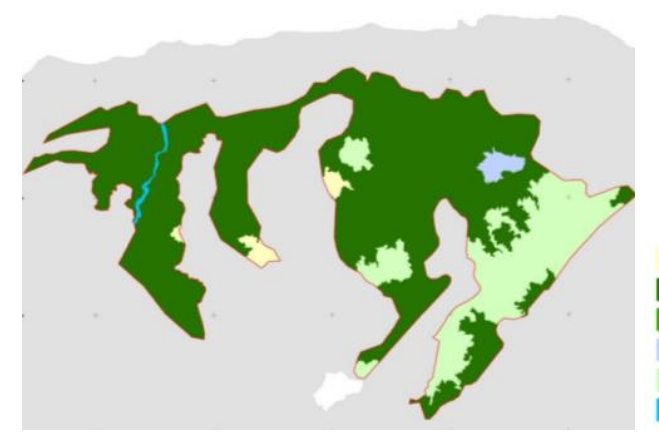

a) tahun 2013

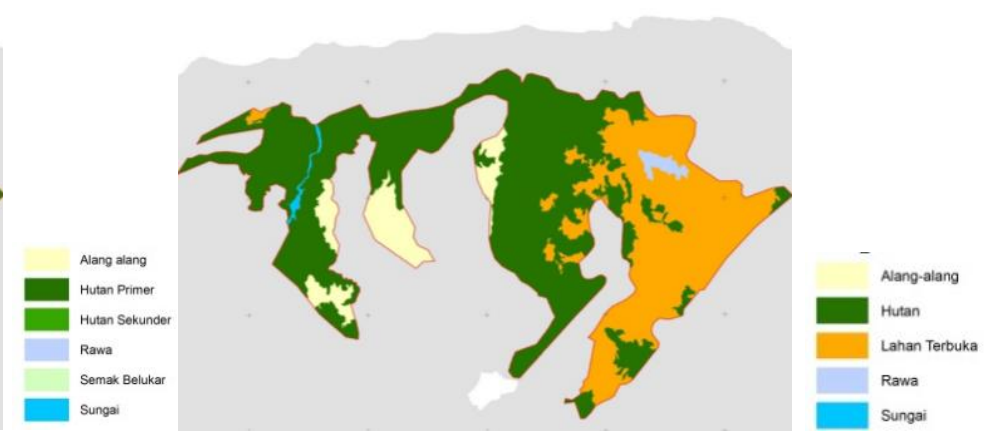

b) tahun 2016

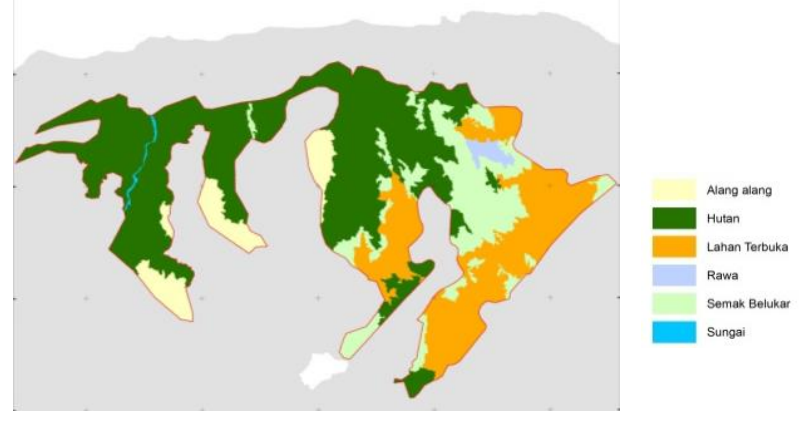

c) tahun 2018

Gambar 1. Peta Tutupan Lahan PT. Gema Hutan Lestari

Hasil klasifikasi baik secara digital maupun visual, pada tahun 2013, 2016 dan tahun 2018 hutan masih mendominasi sebanyak $76,5 \%, 58,51 \%$, dan $50,4 \%$ dibandingkan tutupan lahan lainnya. Luas tutupan lahan pada tiap tahun pengamatan disajikan pada Gambar 2 dan Tabel 2.

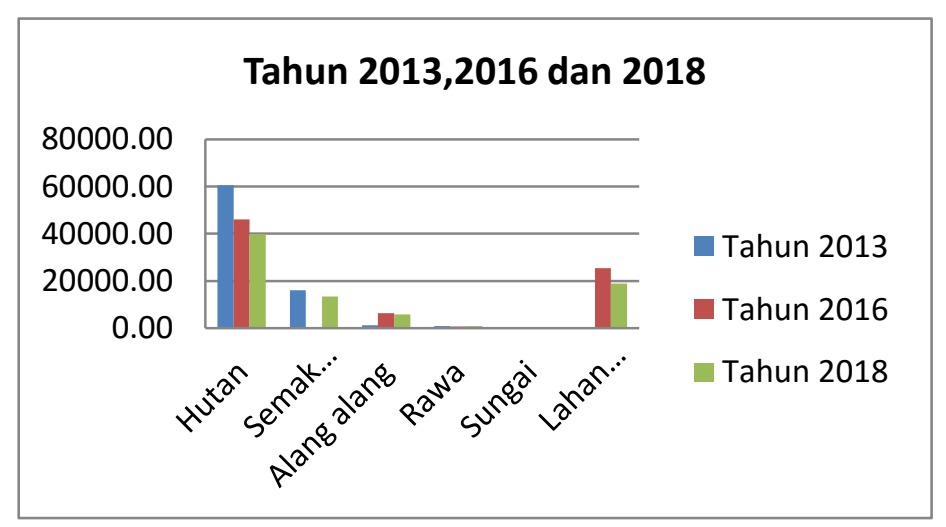

Gambar 2. Grafik Tutupan Lahan Tahun 2013, 2016 dan 2018 
Tabel. 2. Luasan Tutupan Lahan multiwaktu PT. Gema Hutan Lestari.

\begin{tabular}{llrrrrrr}
\hline \multicolumn{8}{c}{ Data Tahun 2013-2018 } \\
\hline No. & $\begin{array}{c}\text { Kelas } \\
\text { Tutupan }\end{array}$ & $\begin{array}{c}\text { Luasan } \\
2013 \\
(\mathrm{Ha})\end{array}$ & \multicolumn{1}{c}{$\%$} & $\begin{array}{c}\text { Luasan } \\
2016(\mathrm{Ha})\end{array}$ & $\%$ & $\begin{array}{c}\text { Luasan } \\
2018(\mathrm{Ha})\end{array}$ & $\%$ \\
\hline 1 & Hutan & 60585.82 & 76.5 & 46060.15 & 58.1 & 39908.12 & 50.4 \\
& Semak & & & & & & \\
3 & Belukar & 16131.90 & 20.4 & 0.00 & 0.0 & 13400.20 & 16.9 \\
4 & Alang alang & 1252.08 & 1.6 & 6475.35 & 8.2 & 5902.21 & 7.5 \\
5 & Rawa & 923.48 & 1.2 & 750.10 & 0.9 & 843.35 & 1.1 \\
6 & Sungai & 320.02 & 0.4 & 416.81 & 0.5 & 267.12 & 0.3 \\
& Lahan & & & & & & \\
7 & Terbuka & 0.00 & 0.0 & 25510.90 & 32.2 & 18892.30 & 23.8 \\
\hline & Total & $79,213.30$ & 100.0 & $79,213.30$ & 100.0 & $79,213.30$ & 100.0 \\
\hline
\end{tabular}

\section{Perubahan tutupan lahan pada tahun} 2013-2016.

Hasil analisis menunjukan perubahan terluas tiap kelas tutupan lahan ialah sebagai berikut, dari tahun 2013 sampai dengan 2016 terjadi perubahan hutan besar besaran dengan luasan 12261,75 ha menjadi lahan terbuka. Perubahan dengan nilai yang sama menjadi lahan terbuka juga terjadi pada semak belukar ditahun sebelumnya dengan luasan 12912.25 ha. Sedangkan pada daerah rawa terjadi perubahan menjadi lahan terbuka sebesar 346.15 ha. Dan untuk tutupan alang-alang dan sungai mengalami deforestasi dengan luasan yang tidak terlalu signifikan, untuk selengkapnya disajikan pada Tabel 3 .

Tabel 3. Perubahan tutupan lahan tahun 2013-2016

\begin{tabular}{|c|c|c|c|c|c|c|c|c|c|}
\hline \multicolumn{10}{|c|}{2016} \\
\hline Tahun & $\begin{array}{l}\text { Kelas } \\
\text { Tutupan }\end{array}$ & & 1 & 2 & 3 & 4 & 5 & 6 & Total \\
\hline \multirow{6}{*}{2013} & Hutan & 1 & 42871.17 & 0.00 & 5138.58 & 174.68 & 128.06 & 12261.75 & 60574.24 \\
\hline & $\begin{array}{l}\text { Semak } \\
\text { Belukar }\end{array}$ & 2 & 3076.78 & 0.00 & 148.23 & 0.00 & 0.00 & 12912.25 & 16137.26 \\
\hline & Alang alang & 3 & 58.86 & 0.00 & 1194.24 & 0.00 & 0.00 & 0.00 & 1253.10 \\
\hline & Rawa & 4 & 0.00 & 0.00 & 0.00 & 579.34 & 0.00 & 346.15 & 925.49 \\
\hline & Sungai & 5 & 29.64 & 0.00 & 0.00 & 0.00 & 293.57 & 0.00 & 323.21 \\
\hline & $\begin{array}{l}\text { Lahan } \\
\text { Terbuka }\end{array}$ & 6 & 0.00 & 0.00 & 0.00 & 0.00 & 0.00 & 0.00 & 0.00 \\
\hline & Total & & 46036.45 & 0.00 & 6481.05 & 754.02 & 421.63 & 25520.15 & 79213.30 \\
\hline
\end{tabular}

\section{Perubahan Tutupan Lahan Pada Tahun} 2016-2018.

Di tahun 2016 sampai dengan tahun 2018 masih terlihat terjadi pengurangan hutan seluas 4830.87 ha menjadi lahan terbuka sehingga hanya 1/3 dari perubahan di periode tahun sebelumnya. Sedangkan terjadi suksesi dari lahan terbuka menjadi semak belukar dengan luasan yang cukup besar yaitu 
8927.99 ha. Pada kondisi tutupan lahan lainnya di periode tahun ini mengalami perubahan dalam skala kecil dengan pertumbuhan tegakan bercampur semak belukar dan tumbuhan berkayu lainnya, dari perubahan yang diamati juga dipengaruhi oleh periode waktu yang singkat dibandingkan periode sebelumnya, dan selengkapnya data disajikan pada Tabel 4.

Tabel 4. Perubahan Tutupan Lahan Tahun 2016-2018

\begin{tabular}{|c|c|c|c|c|c|c|c|c|c|}
\hline \multicolumn{10}{|c|}{2018} \\
\hline Tahun & Kelas Tutupan & & 1 & 2 & 3 & 4 & 5 & 6 & Total \\
\hline \multirow{7}{*}{2016} & Hutan & 1 & 35355.20 & 4464.57 & 1382.77 & 0.00 & 3.04 & 4830.87 & 46036.45 \\
\hline & $\begin{array}{l}\text { Semak } \\
\text { Belukar }\end{array}$ & 2 & 0.00 & 0.00 & 0.00 & 0.00 & 0.00 & 0.00 & 0.00 \\
\hline & Alang alang & 3 & 1958.32 & 0.00 & 4522.73 & 0.00 & 0.00 & 0.00 & 6481.05 \\
\hline & Rawa & 4 & 0.00 & 39.08 & 0.00 & 714.94 & 0.00 & 0.00 & 754.02 \\
\hline & Sungai & 5 & 157.65 & 0.00 & 0.00 & 0.00 & 263.98 & 0.00 & 421.63 \\
\hline & $\begin{array}{l}\text { Lahan } \\
\text { Terbuka }\end{array}$ & 6 & 2405.97 & 8927.99 & 0.00 & 129.70 & 0.00 & 14056.49 & 25520.15 \\
\hline & Total & & 39877.14 & 13431.64 & 5905.50 & 844.64 & 267.02 & 18887.36 & 79213.30 \\
\hline
\end{tabular}

\section{KESIMPULAN DAN SARAN}

\section{Kesimpulan}

1. Tutupan lahan hasil klasifikasi menggunakan citra Landsat 8 OLI/TIRS tahun 2013, 2016, dan 2018 baik secara digital maupun visual terdiri atas hutan, semak belukar, alang-alang, rawa, sungai dan Lahan terbuka.

2. Perubahan tutupan lahan tertinggi yang terjadi pada tahun 2013 sampai dengan tahun 2016 meliputi hutan berubah menjadi lahan terbuka sebesar 12261,75 ha. Semak belukar menjadi lahan terbuka juga mengalami perubahan yang besar seluas 12912,25 ha. Sedangkan tutupan yang lainnya tidak mengalami perubahan yang signifikan. Perubahan tutupan lahan juga terjadi dari tahun 2016 sampai dengan tahun 2018. Perubahan tutupan lahan terbuka menjadi semak belukar sebesar 8927,99 ha. Lahan terbuka mengalami perubahan menjadi semak belukar sehingga luasannya menjadi 18887,36 ha. Hutan menjadi semak belukar seluas 4464.57 ha, dan hutan masih terus mengalami perubahan namun lebih sedikit disbanding periode sebelumnya yaitu seluas 4830.87 ha.

\section{Saran}

Perlu adanya penelitian serupa pada areal IUPHHK-HA PT. Gema Hutan Lestari pada setiap periode waktu 5 tahun atau 10 tahun, sehingga setiap tutupan lahan dapat terpantau dan mengontrol pemanenan secara berkala agar perubahan hutan menjadi non hutan tidak terjadi secara signifikan. 


\section{DAFTAR PUSTAKA}

Direktorat Geologi Bandung. 1968., Peta Geologi Indonesia Pulau Buru Skala 1: 250.000 .

Jaya NS. 2010. Analisis Citra Digital Perspektif Penginderaan Jauh untuk Pengelolaan Sumberdaya Alam. Bogor (ID): Fakultas Kehutanan Institut Pertanian Bogor.

Lilesand TM, Kiefer RW. 1990. Penginderaan Jauh dan Interpretasi Citra. Yogyakarta (ID): Gajah Mada University Press.

Pusat Penelitian Tanah, Bogor, 1993. Jenis dan Macam Tanah di Indonesia.

Puturuhu F., 2017. Pengembangan Metode Penginderaan Jauh dan Sistem Informasi Geografis untuk Pemetaan Kerawanan Longsorlahan di Jazirah Leitimur Pulau Ambon. Disertasi Fakultas Geografi UGM.

Schmidt, F. H dan Ferguson, J. H. A. 1951. Rainfall Types Based On Wet and Dry Period Rations for Indonesia With Western New Guinea. Jakarta: Kementrian Perhubungan Meteorologi dan Geofisika.

Setiyono B. 2006. Deteksi Perubahan Penutupan Lahan Menggunakan Citra Satelit Landsat ETM $^{+}$di Daerah Aliran Sungai (DAS) Juwana, Jawa Tengah. [Skripsi]. Bogor (ID): Institut Pertanian Bogor.

UU RI Nomor 41 Tahun 1999. Tentang Kehutanan.

Wicaksono, MDA. 2006. Deteksi Perubahan Penutupan Hutan Mangrove Menggunakan Data Landsat Di Delta Sungai Mahakam, Kalimantan Timur.
[Skripsi]. Bogor (ID): Institut Pertanian Bogor.

WWF. 2012., Hutan Indonesia: Penyerap atau Pelepas Emisi Gas Rumah Kaca 